\title{
Renovascular Hypertension
}

\author{
${ }^{1}$ Ashish Nandwani, ${ }^{2}$ Vijay Kher
}

\begin{abstract}
Renovascular disease caused by renal artery stenosis leading to reduced renal perfusion can produce a range of clinical conditions ranging from incidental finding on angiography without any hemodynamic significance to renovascular hypertension (RVH) with or without ischemic and hypertensive renal injury. A fall in renal perfusion pressure is sufficient to initiate RVH that only occurs when 70 to $80 \%$ of artery lumen is occluded. Atherosclerosis, fibromuscular dysplasia, and vasculitis involving the renal arteries are the leading causes of renovascular disease. With improvement in imaging studies, significant renal artery stenosis is detected more often than before. Management includes medical therapy aiming at blood pressure control and cardiovascular risk factor management. Renal revascularization is considered in patients with deteriorating renal functions and resistant hypertension.
\end{abstract}

Keywords: Atherosclerotic renovascular disease, Fibromuscular dysplasia, Percutaneous transluminal renal angioplasty, Renin-angiotensin-aldosterone system, Renovascular hypertension.

How to cite this article: Nandwani A, Kher V. Renovascular Hypertension. Hypertens J 2016;2(2):86-95.

Source of support: Nil

Conflict of interest: None

\section{INTRODUCTION}

Hypertension is the leading risk factor for coronary artery disease, cerebrovascular disease, and renal failure. Various randomized controlled trials have shown the benefit of antihypertensive drug therapy in decreasing the morbidity and mortality due to hypertension. In 90 to $95 \%$ of cases with hypertension, the cause of hypertension is unknown. Patients with no identifiable cause for hypertension are classified as primary hypertension or essential hypertension. Patients with identifiable causes of hypertension are designated as secondary hypertension. The commonest causes for secondary

\footnotetext{
${ }^{1}$ Consultant, ${ }^{2}$ Chairman

${ }^{1}$ Department of Nephrology and Renal Transplantation, MedantaThe Medicity, Gurgaon, Haryana, India

2Department of Nephrology and Renal Transplantation, Fortis Escorts Hospital, New Delhi, India

Corresponding Author: Vijay Kher, Chairman, Department of Nephrology and Renal Transplantation, Fortis Escorts Hospital New Delhi, India, Phone: +919811054118, e-mail: vijaykher51@ yahoo.com
}

hypertension are renal parenchymal diseases (2-6\%), renovascular hypertension (RVH) (1-4\%), and endocrine abnormalities (1\%). Coarctation of aorta, inflammatory arteritides, obstructive sleep apnea, and obesity are the other rare causes of secondary hypertension. Approximately $1 \%$ of cases are drug induced, and they are caused by sympathomimetic drugs, decongestants, oral contraceptives, and steroids. ${ }^{1,2}$ It is important to evaluate the patients for secondary causes, as some of these conditions can be cured, leading to withdrawal or reduction of antihypertensive medication. ${ }^{3,4}$ The clinical clues that suggest the likely presence of secondary hypertension are:

- Age $<30$ years with no family history of hypertension and other risk factors.

- An acute rise in blood pressure (BP) in an individual with documented normal BP in recent past.

- Resistant hypertension, which is not controlled on adequate doses of more than three antihypertensive drugs including a diuretic.

- Malignant or accelerated hypertension with papilledema, neurological disturbances, acute kidney injury, or heart failure.

- Flash pulmonary edema and labile BP.

- Episodic headaches, diaphoresis, and palpitations.

\section{RENOVASCULAR HYPERTENSION}

The clinical consequences of renovascular disease with impaired perfusion of the kidneys can lead to rise in arterial pressures designated as RVH with or without ischemic injury to kidney causing irreversible loss of kidney function designated as ischemic nephropathy or azotemic renovascular disease. It is an important and potentially curable cause of secondary hypertension. Majority of patients with RVH have main renal artery stenosis leading to activation of various hormonal and neuronal responses, which causes rise in systemic arterial pressure. The leading causes of renal artery stenosis are atherosclerotic renovascular disease, fibromuscular dysplasia, and vasculitis involving the renal arteries ${ }^{5}$ (Tables 1 and 2).

Renovascular hypertension accounts for less than $1 \%$ of patients with mild to moderate hypertension. ${ }^{6}$ Atherosclerotic renal artery stenosis usually coexists with other manifestations of atherosclerosis, such as coronary artery disease (10-14\%) and peripheral arterial and aortic diseases $(24-35 \%){ }^{6}$ The prevalence of renal artery 
Renovascular Hypertension

\begin{tabular}{ll}
\hline \multicolumn{2}{l}{ Table 1: Artherosclerosis or fibromuscular renal artery disease } \\
\hline Atherosclerosis & Fibromuscular \\
\hline Men and women & Women \\
Age $>50-55$ years & Age 15-40 years \\
Total occlusion may occur & Total occlusion is rare \\
Ischemic atrophy is common & Ischemic atrophy is uncommon \\
Surgical intervention or PTRA & Surgical intervention or \\
cure rates of hypertension are & PTRA good cure rates of the \\
minimal & hypertension \\
Less amenable to PTRA & More amenable to PTRA \\
\hline
\end{tabular}

stenosis in high-risk patients with severe or refractory hypertension is 27 to $45 \%$ in whites when compared with 8 to $19 \%$ in blacks. ${ }^{7}$ In another prospective study, $\mathrm{RVH}$ was present equally in blacks and whites. ${ }^{8}$

\section{CLINICAL CLUES FOR RVH}

The clinical findings associated with likelihood of RVH secondary to significant renal artery stenosis are:

- New onset of severe/resistant hypertension in patients aged $>55$ years.

- Severe hypertension in patients with diffuse atherosclerosis, particularly those aged $>50$ years.

- Deterioration in renal function as defined by rise in serum creatinine by more than $50 \%$ within 1 week of starting therapy with an angiotensin-converting enzyme (ACE) inhibitor or angiotensin II receptor blocker (ARB).

- Severe hypertension in patients with asymmetrical renal sizes with difference of $>1.5 \mathrm{~cm}$ or unilateral unexplained atrophic kidney.

- Abdominal bruit that lateralizes to one side. Abdominal renal bruit has a sensitivity of approximately $40 \%$ but has specificity as high as $99 \%{ }^{9}$

- Recurrent episodes of flash pulmonary edema in patients with severe hypertension or refractory heart failure with impaired renal function. ${ }^{10}$

The 2011 American College of Cardiology/American Heart Association guidelines on Peripheral Artery Disease proposed that diagnostic testing for renal artery stenosis should be done in these settings, and corrective procedure may be considered if renovascular disease is detected. ${ }^{11}$

\section{ETIOLOGY OF RVH}

The most common causes of RVH are stenosis of the main vessel supplying the kidney. The two major causes of main renal artery stenosis are atherosclerotic renovascular disease (ASRVD) and fibromuscular dysplasia (FMD). The latter may be caused by medial, perimedial, intimal fibroplasias, or medial hyperplasia. Atherosclerosis mainly affects male patients above the age of 45 years and usually involves the aortic orifice
Table 2: Types of renal artery disease

\begin{tabular}{ll}
\hline Disease & Incidence \\
\hline Atherosclerosis & $60-0 \mathrm{he}$ \\
Fibrous dysplasia & $20-0 \mathrm{br}$ \\
$\quad$ Medial & $30 \%$ \\
Intimal & $5 \%$ \\
Perimedial & $5 \%$ \\
Arterial aneurysm & $<5 \%$ \\
Arteriovenous malformation & $<1 \%$ \\
\hline
\end{tabular}

or the proximal main renal artery. This is particularly common in patients with diffuse atherosclerosis but can occur as a relatively isolated renal lesion. Fibromuscular dysplasia most often affects women below the age of 50 years and typically involves the distal main renal artery or the intrarenal branches. Other causes include involvement of renal arteries in systemic vasculitis, such as Takayasu arteritis (TA) and polyarteritis, renal artery aneurysm, atheroembolic disease, aortic coarctation, vascular occlusion due to endovascular aortic graft, and external compression by metastatic tumors.

\section{ATHEROSCLEROTIC RENOVASCULAR DISEASE}

Atherosclerotic renovascular disease refers to the atherosclerotic narrowing of the renal arteries that may range from focal stenosis to complete occlusion of one or both renal arteries leading to renal ischemia and subsequent renal atrophy. These luminal atherosclerotic narrowing of the renal arteries is often present in conjunction with macrovascular disease in other organ systems, such as coronary, peripheral, and cerebral arteries. Atherosclerotic plaques are commonly present in the first or the second centimeter of renal artery and may extend into the aorta.

The prevalence of ASRVD is increasing, although this may partly be due to improved imaging and selection bias. United States Renal Data System data from 1991 to 2001 revealed prevalence of ASRVD of $0.54 \%$ in elderly population, and an estimated incidence of new cases between 2000 and 2001 was 3.7 cases per 1000 patient years. ${ }^{12,13}$ In patients undergoing peripheral or coronary angiography, ASRVD was found in 11 to $42 \%$ of cases. Renal artery stenosis may be bilateral in 20 to $40 \%$ of such cases.${ }^{14}$ Risk factors include age $>50$ years, smoking, diabetes mellitus, hyperlipidemia, and hypertension. A positive relationship has been shown in univariate analysis between ASRVD and high-sensitivity C-reactive protein, lipoprotein and homocysteine levels.

Clinically, ASRVD may be detected incidentally while doing coronary or peripheral angiography. This is usually of no significance. Renovascular hypertension is the most common clinical manifestation and may 

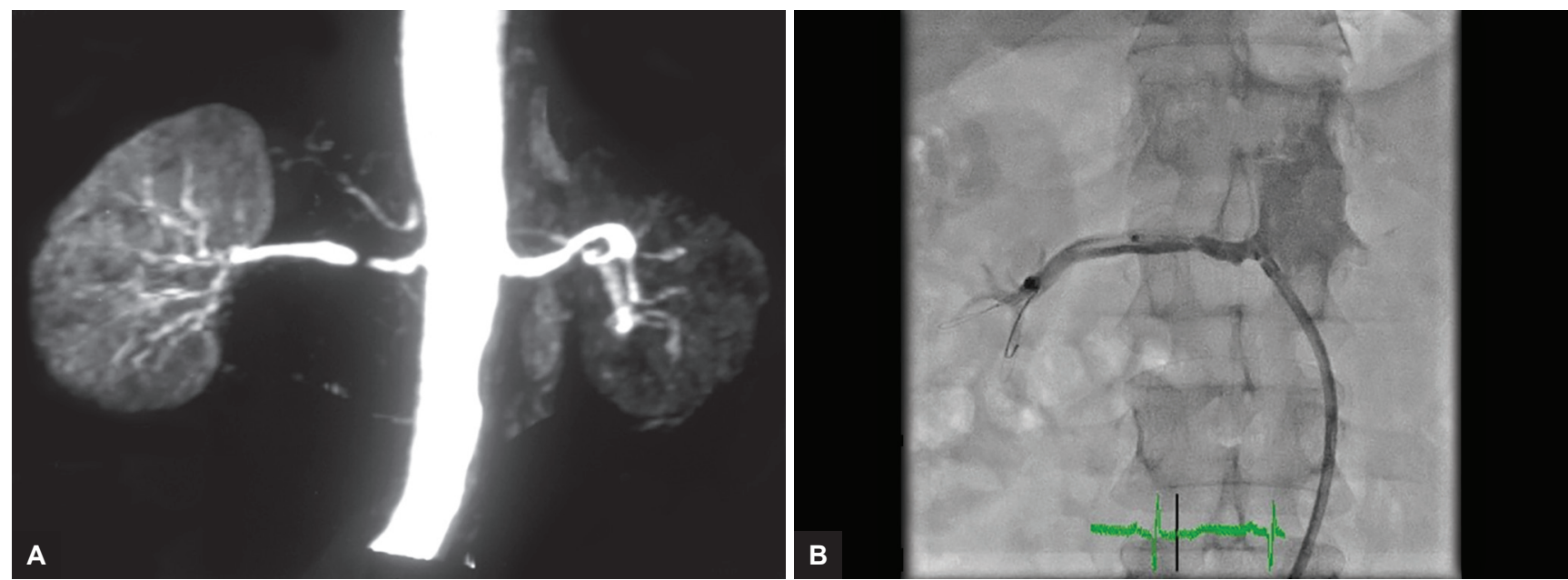

Figs 1A and B: (A) Magnetic resonance angiography showing atherosclerotic right renal artery stenosis, and (B) renal angiography showing atherosclerotic right renal artery stenosis (postangioplasty)

be associated with other target organ damage. Patients with RVH have abnormal circadian rhythm with loss of nocturnal pressure fall. Patients may have resistant hypertension requiring three or more antihypertensive medication. Renin-angiotensin-aldosterone system (RAAS) inhibition with ACE inhibitor or ARBs may lead to acute kidney injury in patients with ASRVD. Patients with advanced disease present with renal impairment progressing to end-stage renal disease (ESRD) or flash pulmonary edema due to rapid volume expansion ${ }^{15-17}$ (Figs $1 \mathrm{~A}$ and $\mathrm{B}$ and $2 \mathrm{~A}$ and $\mathrm{B}$ ).

\section{FIBROMUSCULAR DYSPLASIA}

Fibromuscular dysplasia is an idiopathic noninflammatory, nonatheromatous arteriopathy associated with proliferation of medial smooth muscle cells and fibrous tissue leading to renal artery stenosis. The prevalence of renovascular FMD is estimated at 4 in $1,000{ }^{18}$ The most common age group is 15 to 50 years and $90 \%$ of cases are reported in females. Fibromuscular dysplasia may
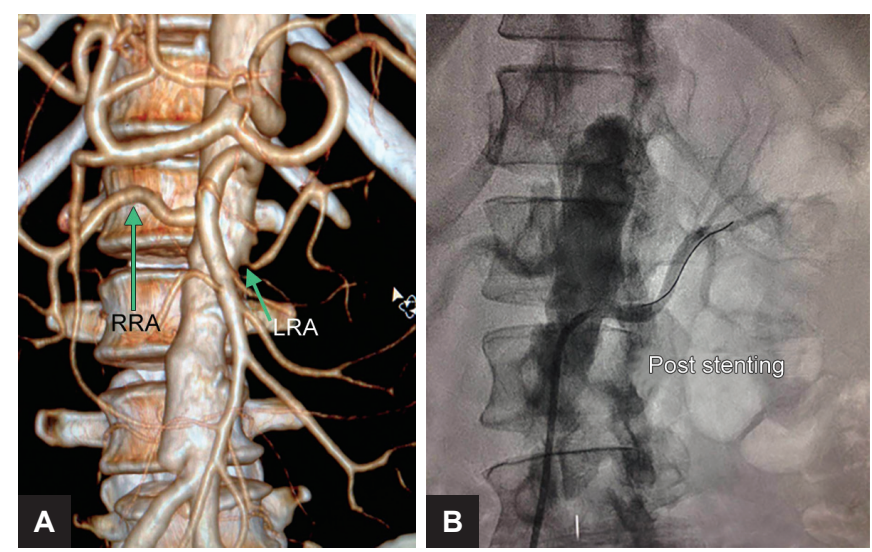

Figs 2A and B: (A) Three-dimensional reconstruction image of CTA showing left renal artery stenosis, and (B) renal angiography showing left renal artery stenosis (postangioplasty) be associated with disorders, such as Marfan syndrome, tuberous sclerosis, Ehlers-Danlos syndrome, and cystic medial necrosis. The vascular distribution of FMD involves mainly renal and cerebral vessels. Renal arteries are involved in 65 to $70 \%$ of cases and cerebrovascular involvement is seen in 25 to $30 \%$ of cases. It may also involve the coronary, mesenteric, and peripheral extremity vessels. ${ }^{19,20}$ Histologically, medial fibroplasia is the commonest variety, and the other rare forms include perimedial fibroplasias and medial hyperplasia. ${ }^{21}$ Angiographically, the characteristic appearance is that of string of beads, with bead diameter larger than lumen ${ }^{22}$ (Fig. 3).

Commonest clinical presentation of FMD is RVH, headaches, dizziness, and pulsatile tinnitus. While hypertension is the leading manifestation of renovascular FMD, some patients may have flank pain due to renal infarction either from dissection of renal artery or embolism from the proximal aneurysm. Flank pain may also be due to the rupture of a renal artery aneurysm with retroperitoneal bleed. Bruits may be present in

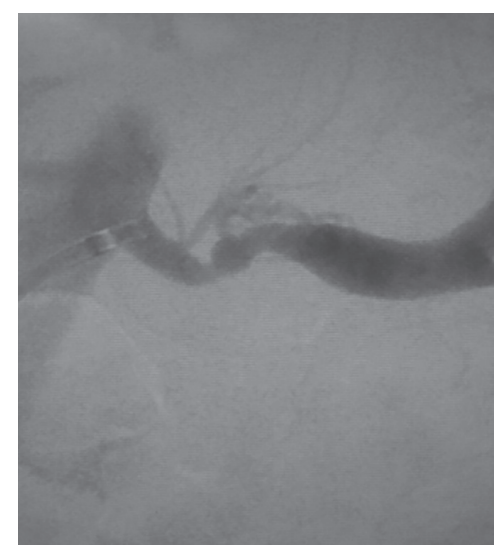

Fig. 3: Renal angiography showing fibromuscular dysplasia of left renal artery 
flanks over carotids and femorals. ${ }^{23-25}$ Progression of FMD has been documented in approximately $27 \%$ cases on serial angiographic examination. Fibromuscular dysplasia rarely causes ESRD unless hypertension is uncontrolled or thrombosis of renal artery results in the renal infarction.

\section{CONGENITAL ARTERITIS}

Renovascular hypertension can also be caused by the congenital abnormalities of vascular development, such as coarctation of aorta and middle aortic syndrome. Congenital coarctation involving abdominal aorta leading to middle aortic syndrome is rare and accounts for $2 \%$ of all coarctation. Proximal renal artery stenosis is present in $80 \%$ of cases and mesenteric arteries may be involved in $25 \%$ of cases. The common clinical features are hypertension, lower limb claudication, headaches, and stroke. Most patients do not live beyond 40 years, if left untreated. Surgical revascularization is required in most cases. ${ }^{26,27}$

\section{INFLAMMATORY ARTERITIS}

Takayasu arteritis (TA) is the commonest inflammatory arteritis leading to RVH. Other rare causes include polyarteritis nodosa, giant cell arteritis, Kawasaki disease, and idiopathic aortitis. Takayasu arteritis is an inflammatory granulomatous arteritis involving aorta and its first-order branches. The prevalence is as high as 1 in 3,000 people in Japan in comparison to only 2.6 cases per million in the USA. It has been reported as the commonest cause of RVH in parts of Asia, especially India. ${ }^{28,29}$

Takayasu arteritis usually presents in the 25 to 40 years age group. The common clinical presentation is fatigue and discomfort in the muscles of one or more extremities, especially upper limbs. There is decreased pulsation of one or both brachial arteries with difference in systolic BP in both arms. Bruit may be heard on abdominal aorta or subclavian arteries. Hypertension due to proximal renal artery stenosis may be the sole manifestation in some cases. Diagnosis is usually based on angiographic findings of narrowing or occlusion of aorta and its primary branches ${ }^{30}$ (Figs $4 \mathrm{~A}$ and B).

\section{RADIATION-INDUCED RENOVASCULAR DISEASE}

Renovascular hypertension is the uncommon complication of the abdominal radiation. Hypertension develops even decades following abdominal radiation for lymphoma or seminoma. Clues for radiation-induced renovascular disease include segmental renal atrophy along with hepatic and retroperitoneal fibrosis and focal aortic calcification. ${ }^{31}$
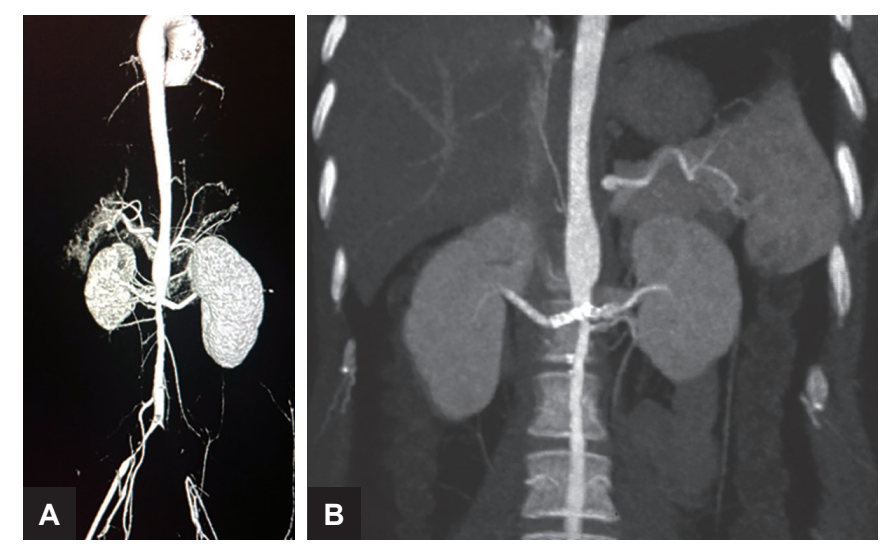

Figs 4A and B: (A) Three-dimensional reconstruction image of CTA in the case of TA showing aneurysmal dilatation of descending aorta, right renal artery stenosis with collateral formations, narrowing of infrarenal aorta, and iliac arteries with complete occlusion of left internal iliac artery, and (B) Computed tomographic angiography in the case of TA postangioplasty with stenting

\section{PATHOPHYSIOLOGY AND MANIFESTATIONS OF RENOVASCULAR DISEASE}

The presence of renal vascular abnormalities may be incidental, and it can be identified in patients undergoing vascular imaging for other reasons, such as coronary angiography or peripheral vascular angiography. These incidental stenoses are usually of little or no hemodynamic significance. Renovascular hypertension refers to rise in arterial pressure secondary to hemodynamically significant renal artery stenosis leading to reduced renal perfusion. Luminal occlusion of 70 to $80 \%$ is usually present before changes in blood flow or pressure across the lesion can be detected. The presence of critical stenosis with reduction in renal perfusion pressure leads to activation of pressor pathways, notably release of renin from juxtaglomerular apparatus leading to activation of RAAS. The rise in angiotensin II and aldosterone increases the systemic arterial pressure to restore the renal perfusion. Additional mechanisms contributing to the elevation of the arterial pressure include activation of sympathetic nervous system, release of endothelin, and decrease in nitric oxide generation. ${ }^{32}$

Underlying mechanisms responsible for the RVH in humans depend on whether renal artery stenosis is unilateral or bilateral. The nomenclature used for these conditions are two-kidney-one-clip hypertension (Goldblatt), in which one clip is present with normal contralateral kidney and one-kidney-one-clip hypertension, in which entire kidney mass is affected as in bilateral renal artery stenosis or stenosis of the solitary kidney. In the former, due to renal hypoperfusion, there is activation of RAAS leading to sodium retention due to rise in angiotensin II and aldosterone levels. However, presence of normal contralateral kidney allows pressure natriuresis to eliminate excess of sodium. This leads to continuous activation of 
RAAS in the stenotic kidney. These sequences of events are responsible for the angiotensin II-dependent hypertension and secondary hyperaldosteronism.

In one-kidney-one-clip hypertension, entire renal mass is hypoperfused leading to RAAS activation with sodium and water retention; however, there is no contralateral or normal kidney to counteract these changes. With sodium retention and volume expansion, there is negative feedback to inhibit the RAAS activation resulting in decrease in angiotensin II levels. Thus, under this situation, the hypertension is not angiotensin II dependent. ${ }^{33,34}$

\section{DIAGNOSIS OF RVH}

The diagnosis of the RVH depends on demonstrating both critical stenosis of renal artery and activation of RAAS. These include both invasive and noninvasive imaging modalities. The goal of these diagnostic techniques is to establish the presence of renal artery stenosis, its location, and type, whether fibromuscular dysplasia or atherosclerotic lesion. The lesion may be unilateral or bilateral. It is also important to establish the hemodynamic severity of stenotic lesion. If any endovascular intervention is planned, it is important to know the location and degree of the lesion. The gold standard for diagnosing renal artery stenosis is renal angiography. However, it is associated with risk of contrast-induced nephrotoxicity, i.e., more commonly in patients with already compromised renal functions.

Common noninvasive modalities include duplex Doppler ultrasonography (USG), computed tomographic angiography (CTA), and magnetic resonance angiography (MRA). The choice of test depends upon institutional expertise and patient factors. If the noninvasive test is not conclusive and the clinical suspicion remains high, conventional renal angiography is recommended.

Functional studies to assess renal function include captopril renal scintigraphy, which is also useful to determine the relative function of each kidney. Physiologic studies to assess the renin-angiotensin system include selective renal vein renin measurements and plasma renin activity (PRA). These tests are not useful as initial diagnostic tests for renal artery stenosis.

\section{DUPLEX DOPPLER ULTRASONOGRAPHY}

Doppler USG is used for renal vascular anatomy and functional status. Apart from direct visualization of main renal arteries via B-mode imaging, variety of hemodynamic factors including renal blood flow can be measured via Doppler USG. The narrowing of renal artery will cause velocity change and waveform change commensurating with the degree of the stenosis. The waveform becomes dampened downstream the stenosis site. Parameters measured using
Doppler USG include peak systolic velocity at various sites along the aorta and renal arteries, acceleration time and index, and intrarenal resistive index. Doppler USG is used to obtain the renal resistive index, which is calculated from the following formula:

\section{(Peak systolic velocity - end diastolic velocity) $\div$ Peak systolic velocity}

Lesions can also be detected by comparing the systolic flow velocity in the renal artery to that in the aorta since the velocity of flow increases as the artery narrows; end diastolic velocity may also be increased distal to a stenotic lesion.

Features of significant renal artery stenosis are:

- Elevated peak systolic velocity: Velocities in the stenotic segment $>1.8$ to $2.0 \mathrm{~m} / \mathrm{s}$ correlate well with stenosis of $>60 \%$ diameter reduction.

- Renal artery/aorta ratio (RAR): An RAR > 3.5 correlates with stenosis $>60 \%$

- Acceleration time (AT): An AT >0.07 s correlates with a stenosis $>60 \%$

- Loss of the early systolic peak (ESP): Proximal stenosis results in changes to the intrarenal waveform with loss of the ESP and a "tardus parvus" appearance.

Using these criteria, sensitivity and specificity with angiographic estimation of lesions exceeding $>60 \%$ are 90 and $96 \%$ respectively.

Doppler USG is an inexpensive, noninvasive test and is widely available, and it is also suitable for serial measurements to determine disease progression. This modality can also be used to detect recurrent stenosis in patients previously treated with endovascular angioplasty or stenting.

However, limitations include that this is operator dependent and may be difficult to perform in obese patients. It may not identify the small accessory vessels. Further, Doppler USG will not be able to differentiate between fibromuscular dysplasia and atherosclerotic lesion.

A meta-analysis of 88 studies involving 8,147 patients assessed the ability of the various USG parameters to detect renal artery stenosis. Of these parameters, peak systolic velocity, with a sensitivity and specificity of 85 and $92 \%$ respectively, was more accurate than the renal-aortic ratio and acceleration index. The positive predictive value was $84 \%$ and the false-positive rate was $8 \%{ }^{35,36}$

The utility of the resistive index was evaluated in 138 patients with renal artery stenosis. The outcomes were poor among the patients with a resistive index above 0.8. A high resistance index may indicate irreversible intrarenal vascular disease. ${ }^{37-39}$ Determination of the resistive index is operator dependent and can be obscured by patient factors, such as obesity. 


\section{COMPUTED TOMOGRAPHIC ANGIOGRAPHY}

A spiral computed tomography (CT) scan with intravenous contrast injection is a highly accurate noninvasive diagnostic test, which provides excellent images of both kidneys and the vascular tree. It can identify small as well as accessory vessels. Computed tomographic angiography continues to evolve technically and provide excellent sensitivity (96\%) and specificity (97\%) in small groups of patients. The performance of CTA was less favorable than magnetic resonance angiography in a series of 356 hypertensive patients, out of whom 72 patients had some degree of renal artery stenosis. The sensitivity and specificity of CTA were 64 and $92 \%$ respectively. The poor sensitivity of CTA was probably due to the high proportion of patients having FMD, as fibromuscular disease usually involves distal arterial segments that are difficult to image. ${ }^{40,41}$

The risk of contrast-induced nephrotoxicity is high especially in patients with impaired renal functions due to underlying ischemic nephropathy. Computed tomography imaging with three-dimensional reconstruction and higher resolution with less contrast use continue to improve the value of CTA as a diagnostic tool for renovascular disease.

\section{MAGNETIC RESONANCE ANGIOGRAPHY}

Magnetic resonance angiography with gadolinium contrast gives excellent vascular imaging of the renal arteries. This technique is useful in patients who cannot be given iodinated contrast agent due to either allergic reactions or impaired renal functions due to risk of contrast-induced nephrotoxicity. There are concerns about gadoliniumassociated complications, especially nephrogenic systemic fibrosis in patients with glomerular filtration rate (GFR) $<30 \mathrm{~mL} / \mathrm{min} / 1.73 \mathrm{~m}^{2}$. Magnetic resonance angiography is a highly sensitive technique for detecting proximal renal artery stenosis with sensitivity of 83 to $100 \%$ and specificity of 92 to $97 \%$. Limitations of MRA include overestimation of luminal narrowing and limited sensitivity for middle and distal vascular lesions. ${ }^{40}$ Patients with metallic stents are not candidates for MRA.

Using arteriography as the gold standard, MRA had a sensitivity of $100 \%$ and specificity of $96 \%$ for the detection of stenosis of the main renal arteries. ${ }^{42}$ The use of breathhold MRA with paramagnetic contrast material improves the ability to visualize small accessory arteries. Blood oxygen level-dependent magnetic resonance imaging is a noninvasive method that detects local levels of the deoxyhemoglobin without requiring contrast.

\section{INVASIVE IMAGING - RENAL ANGIOGRAPHY}

Renal angiography remains the gold standard for defining the stenotic lesions of renal vasculature. It can identify whether stenosis is unilateral or bilateral, atherosclerotic or fibromuscular dysplasia, and poststenotic dilatation. Angiography provides important anatomic and functional information including delayed perfusion and collateral and accessory renal vessels. It is also useful for planning the endovascular procedure, such as angioplasty and stenting.

Contrast-induced nephrotoxicity and catheter-related complications are main issues associated with renal angiography. Atherosclerotic disease, diabetes mellitus, old age, impaired renal functions, and dehydration are main risk factors for contrast-induced nephrotoxicity. Although renal angiography is the gold standard for diagnosing renal artery stenosis, its invasive nature, cost, and potential complications make it suitable only for those patients in whom renal vascular intervention is planned.

\section{CAPTOPRIL RENOGRAM}

Radionuclide imaging provides a functional assessment of the kidneys allowing the comparison of blood flow and GFR between two kidneys. Diethylenetriaminepentaacetic acid and MAG3 are the commonly used radiopharmaceuticals used for radionuclide renography. MAG3 may be more reliable in patients with renal insufficiency. MAG3 also has clearance characteristic similar to hippuran and represents the renal blood flow. Change in the GFR after ACE inhibition allows inferences regarding the presence of renal artery stenosis. When this test is completely negative, it has a high negative predictive value.

Nonstimulated radionuclide scans have a false-negative rate of 20 to $5 \%$. The predictive value can be increased by administration of oral captopril (25-50 mg) 1 hour before the isotope is injected. The interpretation of captopril renogram is based upon the ACE inhibitor-induced decline in GFR in the stenotic kidney, accompanied by an increase in GFR in the contralateral kidney due to removal of angiotensin II-mediated vasoconstriction. The net result is that the difference between the two kidneys is enhanced.

The sensitivity and specificity of the captopril renogram vary substantially in different studies and has a poor correlation with the benefit obtained from angioplasty. The sensitivity and specificity range from 65 to $96 \%$ and 62 to $100 \%$ respectively, in several series. Sensitivity further decreases in the presence of the renal insufficiency with reduced GFR (serum creatinine $>2.0 \mathrm{mg} / \mathrm{dL}$ ). ${ }^{43,44}$ As a result of these limitations, captopril renography is not broadly helpful in diagnosing renal artery stenosis, and the major use is to determine the relative function of each kidney.

\section{PLASMA RENIN ACTIVITY}

Peripheral venous PRA demonstrates the activation of renin-angiotensin system as a marker of underlying 
RVH. Plasma renin activity is elevated in only 50 to $80 \%$ of patients with RVH. Levels of PRA may be suppressed by a high dietary sodium intake, bilateral renal arterial disease, volume expansion related to intrinsic kidney disease, and various antihypertensive drugs. It has limited value for the diagnosis of RVH as both sensitivity and specificity are low.

The predictive value of the PRA can be increased by measuring the rise in PRA 1 hour after the administration of 25 to $50 \mathrm{mg}$ of captopril. Patients with renal artery stenosis have an increase in the PRA as compared with normal individuals due to the removal of the normal suppressive effect of high angiotensin II levels on renin secretion in the stenotic kidney. ${ }^{45}$

\section{MEASUREMENTS OF RENAL VEIN RENIN}

Measurement of renal vein renin levels helps to lateralize the stenotic kidney ( $>1.5: 1$ stenotic-nonstenotic kidney ratio). This discrepancy in renin secretion between the two kidneys is present in less than $10 \%$ of normal individuals. Thus, the presence of highly lateralizing renal renin values indicates the presence of physiologically significant renal artery stenosis. The accuracy of these measurements may be enhanced by administration of an ACE inhibitor and/or diuretics, which will increase renin secretion on the affected side.

The overall sensitivity of renal vein rennin measurement is $65 \%$ and positive predictive value is $18.5 \%$. Renal vein renins have a limited role in estimating the physiologic significance of a stenotic lesion. Exceptions may include patients with bilateral renal artery stenosis in whom renal vein renin measurements can be used to determine which side contributes most to the hypertension or in patients considered for nephrectomy of a pressor kidney. ${ }^{46}$

These noninvasive tests, peripheral PRA, stimulated PRA, renal vein renin level, and the captopril renogram are no longer considered suitable for initial testing patients with suspected renovascular disease because of their poor sensitivity and specificity, and thus, they have no meaningful role.

\section{MANAGEMENT OF RVH}

Once a patient is diagnosed with renal artery stenosis leading to RVH, it is important to know whether the lesion is unilateral or bilateral and likely cause of renal artery stenosis, that is, atherosclerotic or FMD or inflammatory. The main therapeutic options available are:

- Medical therapy

- Percutaneous angioplasty with or without stenting

- Surgical revascularization, or in some cases, resection of a "pressor" kidney
Perhaps, the most difficult aspect of management of $\mathrm{RVH}$ is whether to treat medically or proceed for revascularization procedure. General approaches in patients with RVH include control of hypertension by medical therapy. Revascularization is reasonable in patients who have short duration of BP elevation prior to the diagnosis of renovascular disease or in patients who do not respond to optimal medical therapy or are intolerant to medical therapy. Patients with recurrent flash pulmonary edema and/or refractory heart failure may also require revascularization procedure. In addition, revascularization may be required in patients having progressive renal insufficiency due to bilateral renal artery stenosis (or unilateral stenosis to a solitary functioning kidney). ${ }^{47}$

\section{MEDICAL THERAPY}

Angiotensin-converting enzyme inhibitors and ARBs are most effective drugs to control BP in patients with renovascular disease. If $\mathrm{BP}$ goals are not achieved with angiotensin inhibition alone, other antihypertensive drugs, such as a calcium channel blocker, thiazide diuretic, a mineralocorticoid receptor antagonist, or a beta blocker, should be added as necessary. The potential concerns associated with medical treatment are progressive worsening of stenotic lesion over a period of time leading to impaired renal functions due to ischemic damage. Angiotensin inhibition may lead to acute kidney injury and hyperkalemia. ${ }^{48-50}$

The clinical characteristics associated with poor response to antihypertensive therapy include advanced age, advanced renal insufficiency (serum creatinine $>3.0$ $\mathrm{mg} / \mathrm{dL}$ ), atherosclerotic as opposed to FMD, and small kidneys on imaging.

\section{ENDOVASCULAR TREATMENT OF RENAL ARTERY STENOSIS}

For patients with renal artery stenosis with uncontrolled hypertension, deterioration in renal function, and cardiac failure, revascularization may restore the renal blood flow and stabilize the renal function. There is good data that stent placement is superior to angioplasty alone, especially in ostial stenosis. Patients with FMD are usually treated with angioplasty without stenting. The risks associated with the procedure are renal artery dissection, embolization into the kidney, rupture of renal artery, and contrast-induced nephrotoxicity.

\section{REVASCULARIZATION VS MEDICAL THERAPY ALONE}

Multiple randomized trials have compared revascularization using percutaneous transluminal renal angioplasty (PTRA) with or without stent in combination 
with medical therapy in patients with atherosclerotic renovascular disease.

The largest and most recent of these was the Cardiovascular Outcomes in Renal Atherosclerotic Lesions (CORAL) trial, ${ }^{51}$ which included 947 patients, who had unilateral or bilateral atherosclerotic renal artery stenosis. These patients had systolic hypertension despite two or more antihypertensive medications and/or an estimated GFR (eGFR) $<60 \mathrm{~mL} / \mathrm{min} / 1.73 \mathrm{~m}^{2}$. All patients received a combination of antiplatelet therapy and standardized medical treatments for diabetes, hypertension, and hyperlipidemia. Candesartan was given as an angiotensin receptor blocking agent to all the patients. Patients were then randomly assigned to revascularization or to no revascularization.

The primary outcomes were a composite of cardiovascular or renal death, stroke, myocardial infarction, hospitalization for heart failure, a reduction in eGFR by more than $30 \%$, or ESRD. After a median of 3.6 years, revascularization had no additional effect on the primary outcome as compared with medical therapy alone (35.1 vs 35.8\%). Further, revascularization had no effect on any of the individual components of the primary outcome. The most frequent complication was renal artery dissection, which occurred in 11 (2.2\%) revascularized patients.

The angioplasty and stenting for renal artery lesion trial (ASTRAL) ${ }^{52}$ and stent placement in patients with atherosclerotic renal artery stenosis and impaired renal function trial (STAR $)^{53}$ randomized patients to medical therapy or intervention. All classes of antihypertensives were used. Angiotensin-converting enzyme inhibitors were used in two-thirds of patients in STAR and 38\% patients in the ASTRAL trial. There were no significant differences in the BP control, number of antihypertensive medications, renal functions, or cardiovascular outcomes in these patients.

A meta-analysis, including CORAL and ASTRAL, has been published. ${ }^{54}$ Patients treated with PTRA with or without stent required an average of 0.2 lesser antihypertensive medications. However, there was no difference with regard to change in renal function or the incidence of heart failure, stroke, myocardial infarction, or total mortality. Periprocedural complications associated with PTRA varied across these trials; procedure-related deaths occurred in $0.4 \%$ of patients and renal artery perforations or dissections occurred in $2.5 \%$. Apart from slight reduction in antihypertensive medication, none of these studies demonstrated any significant clinical benefit from PTRA. 51-53,55-58

Earlier studies by Van Jaarsveld et $\mathrm{al}^{56}$ and Plouin et $\mathrm{al}^{57}$ evaluated BP control in patients with medical therapy vs PTRA in patients who required two or more antihypertensive drugs for BP control and serum creatinine $<2.3 \mathrm{mg} / \mathrm{dL}$. The study was unable to demonstrate any benefit in respect of renal function or event-free survival. They concluded that angioplasty had little advantage over antihypertensive therapy and final BP was not different between the groups.

The main drawbacks of these studies are that highrisk group patients were excluded, who may have benefited most from the procedure, e.g., patients with bilateral RAS, recurrent pulmonary edema, and renal dysfunction.

In summary, these trials demonstrate that most of the patients with ASRVD can be effectively managed with optimal medical therapy with antihypertensive therapy as compared with PTRA with or without stent therapy. No difference in patient survival or renal function could be identified. In most of these studies, ACE inhibitors or ARBs were used and were well tolerated without any significant side effects. Risk associated with revascularization include contrast-induced nephrotoxicity and procedurerelated complications including arterial dissection and segmental renal infarction.

\section{SURGICAL REVASCULARIZATION}

Surgical revascularization carries a considerable risk, cost, and morbidity. It is reserved for patients who fail medical and endovascular therapies or have associated aortic disease, i.e., not amenable to endovascular therapy. Some patients with total occlusion of renal artery resulting in nonfunctioning kidney may require nephrectomy for control of BP.

\section{CONCLUSION}

Renovascular hypertension caused by renal artery stenosis is an important cause of secondary hypertension, especially in elderly patients with other atherosclerotic diseases. Most of the patients can be managed by medical means by antihypertensive medications and measures to prevent atherosclerotic progression with statin therapy. These patients need to be reviewed at regular intervals for progression of disease. Development of resistant hypertension, deteriorating renal functions, and flash pulmonary edema despite medical and diuretic therapy may warrant revascularization therapy. Long-term follow-up for BP control and renal functions is important because of potential recurrent disease or restenosis after revascularization.

\section{ACKNOWLEDGMENT}

Authors would like to acknowledge Dr. Virender Sheorain for providing images for the article. 


\section{REFERENCES}

1. Calhoun DA, Jones D, Textor S, Goff DC, Murphy TP, Toto RD, White A, Cushman WC, White W, Sica D, et al. Resistant hypertension: diagnosis, evaluation, and treatment: a scientific statement from the American Heart Association Professional Education Committee of the Council for High Blood Pressure Research. Hypertension 2008 Jun;51(6):1403-1419.

2. Faselis C, Doumas M, Papademetriou V. Common secondary causes of resistant hypertension and rational for treatment. Int J Hypertens 2011;2011:236239.

3. Lewin A, Blaufox MD, Castle H, Entwisle G, Langford H. Apparent prevalence of curable hypertension in the Hypertension Detection and Follow-up Program. Arch Intern Med 1985 Mar;145(3):424-427.

4. Borgel J,Springer S, Ghafoor J, Arndt D, Duchna HW, Barthel A, Werner S, Van Helden J, Hanefeld C, Neubauer H, et al. Unrecognized secondary causes of hypertension in patients with hypertensive urgency/emergency: prevalence and co prevalence. Clin Res Cardiol 2010 Aug;99(8):499-506.

5. Textor SC, Lerman L. Renovascular hypertension and ischemic nephropathy. Am J Hypertens 2010 Nov;23(11):1159-1169.

6. Davis BA, Crook JE, Vestal RE, Oates JA. Prevalence of renovascular hypertension in patients with grade III or IV hypertensive retinopathy. N Engl J Med 1979 Dec 6;301(23): 1273-1276.

7. Novick AC, Zaki S, Goldfarb D, Hodge EE. Epidemiologic and clinical comparison of renal artery stenosis in black patients and white patients. J Vasc Surg 1994 Jul;20(1):1-5.

8. Svetkey LP, Kadir S, Dunnick NR, Smith SR, Dunham CB, Lambert M, Klotman PE. Similar prevalence of renovascular hypertension in selected blacks and whites. Hypertension 1991 May;17(5):678-683.

9. Turnbull JM. The rational clinical examination. Is listening for abdominal bruits useful in the evaluation of hypertension? JAMA 1995 Oct 25;274(16):1299-1301.

10. Messerli FH, Banglore S, Makani H, Makani H, Rimoldi SF, Allemann Y, White CJ, Textor S, Sleight P. Flash pulmonary oedema and bilateral renal artery stenosis: the Pickering syndrome. Eur Heart J 2011 Sep;32(18):2231-2235.

11. Rooke TW, Hirsch AT, Misra S, Sidawy AN, Beckman JA, Findeiss LK, Golzarian J, Gornik HL, Halperin JL, Jaff MR, et al. 2011 ACCF/AHA Focused Update of the Guideline for the Management of Patients With Peripheral Artery Disease (updating the 2005 guideline): a report of the American College of Cardiology Foundation/American Heart Association Task Force on Practice Guidelines. J Am Coll Cardiol 2011 Nov 1;58(19):2020-2045.

12. Kalra PA, Guo H, Kausz AT, Gilbertson DT, Liu J, Chen SC, Ishani A, Collins AJ, Foley RN. Atherosclerotic renovascular disease in United States patients aged 67 years or older: risk factors, revascularization and prognosis. Kidney Int 2005 Jul;68(1):293-301.

13. Kalra PA, Guo H, Gilbertson DT, Liu J, Chen SC, Ishani A, Collins AJ, Foley RN. Atherosclerotic renovascular disease in United States. Kidney Int 2010 Jan;77(1):37-43.

14. Khosla S, Kunjummen SI, Manda R, Khaleel R, Kular R, Gladson M, Razminia M, Guerrero M, Trivedi A, Vidyarthi V, et al. Prevalence of renal artery stenosis requiring revascularization in patients initially referred for coronary angiography. Catheter Cardiovasc Interv 2003 Mar;58(3):400-403.
15. De Mast Q, Beutler JJ. The prevalence of atherosclerotic renal artery stenosis in risk groups: a systematic literature review. J Hypertens 2009 Jul;27(7):1333-1340.

16. Appel RG, Bleyer AJ, Reavis S, Hansen KJ. Renovascular disease in older patients beginning renal replacement therapy. Kidney Int 1995 Jul;48(1):171-176.

17. Keddis M, Garovic V, Bailey K, Wood CM, Raissian Y, GrandeJP. Ischaemic nephropathy secondary to atherosclerotic renal artery stenosis-clinical and histopathology. Nephrol Dial Transplant 2010 Nov;25(11):3615-3622.

18. Olin JW, Froehlich J, Gu X, Bacharach JM, Eagle K, Gray BH, Jaff MR, Kim ES, Mace P, Matsumoto AH, et al. The United States Registry for Fibromuscular Dysplasia: results in the first 447 patients. Circulation 2012 Jun 26;125(25):3182-3190.

19. Plouin PF, Perdu J, La Batide-Alanore A, Boutouyrie P, Gimenez-Roqueplo AP, Jeunemaitre X. Fibromuscular dysplasia. Orphanet J Rare Dis 2007 Jun 7;2:28.

20. Olin JW, Gornik HL, Bacharach JM, Biller J, Fine LJ, Gray BH, Gray WA, Gupta R, Hamburg NM, Katzen BT, et al. Fibromuscular dysplasia: state of the science and critical unanswered questions: a scientific statement from the American Heart Association. Circulation 2014 Mar;129(9):1048-1078.

21. Alimi Y, Mercier C, Pellissier JF, Piquet P, Tournigand P. Fibromuscular disease of renal artery: a new histopathological classification. Ann Vasc Surg 1992 May;6(3):220-224.

22. Meaney TF. Progression of renal artery fibromuscular dysplasia in 42 patients as seen on angiography. Radiology 1982 Jan;142(1):252-253.

23. Olin JW, Sealove BA. Diagnosis, management, and future developments of fibromuscular dysplasia. J Vasc Surg 2011 Mar;53(3):826-836.

24. Slovut DP, Olin JW. Fibromuscular dysplasia. N Engl J Med 2004 Apr 29;350(18):1862-1871.

25. Persu A, Touze E, Mousseaux E, Barrel X, Joffre F, Plouin PF. Diagnosis and management of fibromuscular dysplasia: an expert consensus. Eur J Clin Invest 2012 Mar;42(3):338-347.

26. Rosenthal E. Coarctation of aorta from fetus to adult: curable condition or life long disease process? Heart 2005 Nov;91(11): 1495-1502.

27. Kenny D, Polson JW, Martin RP, Paton JF, Wolf AR. Hypertension and coarctation of aorta: an inevitable consequence of developmental pathophysiology. Hypertens Res 2011 May;34(5):543-547.

28. Ishikawa K. Diagnostic approach and proposed criteria for the clinical diagnosis of Takayasu's arteriopathy. J Am Coll Cardiol 1988 Oct;12(4):964-972.

29. Sharma BK, Jain S, Suri S, Numano F. Diagnostic criteria for Takayasu arteritis. Int J Cardiol 1996 Aug; (Suppl 54):S141-S147.

30. Tann OR, Tulloh RM, Hamilton MC. Takayasu disease: a review. Cardiol Young 2008 Jun;18(3):250-259.

31. Fakhouri F, La Batide AA, Rerolle JP, Guery B, Raynaud A, Plouin PF. Presentation and revascularization outcome in patients with radiation induced renal artery stenosis. Am J Kidney Dis 2001 Aug;38(2):302-309.

32. Martinez-Maldonado M. Pathophysiology of renovascular hypertension. Hypertension 1991 May;17(5):707-719.

33. Navar LG, Zou L, Von Thun A, Tarng Wang C, Imig JD, Mitchell KD. Unraveling the mystery of Goldblatt hypertension. News Physiol Sci 1998 Aug;13:170-176.

34. Crowley SD, Gurley SB, Oliverio MI, Pazmino AK, Griffiths R, Flannery PJ, Spurney RF, Kim HS, Smithies O, Le TH, et al. Distinct roles for the kidney and systemic tissues in 
blood pressure regulation by the renin angiotensin system. J Clin Invest 2005 Apr;115(4):1092-1099.

35. Williams GJ, Macaskill P, Chan SF, Karplus TE, Yung W, Hodson EM, Craig JC. Comparative accuracy of renal duplex sonographic parameters in the diagnosis of renal artery stenosis: paired and unpaired analysis. Am J Roentgenol 2007 Mar;188(3):798-811.

36. Radermacher J, Chavan A, Bleck J, Vitzthum A, Stoess B, Gebel MJ, Galanski M, Koch KM, Haller H. Use of Doppler ultrasonography to predict the outcome of therapy for renalartery stenosis. N Engl J Med 2001 Feb;344(6):410-417.

37. Ikee R,KobayashiS,Hemmi N,Imakiire T,Kikuchi Y,Moriya H, Suzuki S, Miura S. Correlation between the resistive index by Doppler ultrasound and kidney function and histology. Am J Kidney Dis 2005 Oct;46(4):603-609.

38. Krumme B, Hollenbeck M. Doppler sonography in renal artery stenosis - does the Resistive Index predict the success of intervention? Nephrol Dial Transplant 2007 Mar;22(3): 692-696.

39. Crutchley TA, Pearce JD, Craven TE, Stafford JM, Edwards MS, Hansen KJ. Clinical utility of the resistive index in atherosclerotic renovascular disease. J Vasc Surg 2009 Jan;49(1): 148-155.

40. Glockner JF, Vrtiska TJ. Renal MR and CT angiography: current concepts. Abdomen Imaging 2007 Jun;32(3):407-420.

41. Olbricht CJ,Paul K, Prokop M, Chavan A, Schaefer-Prokop CM, Jandeleit K, Koch KM, Galanski M. Minimally invasive diagnosis of renal artery stenosis by spiral computed tomography angiography. Kidney Int 1995 Oct;48(4):1332-1337.

42. Vasbinder GB, Nelemans PJ, Kessels AG, Kroon AA, Maki JH, Leiner T, Beek FJ, Korst MB, Flobbe K, de Haan MW, et al. Accuracy of computed tomographic angiography and magnetic resonance angiography for diagnosing renal artery stenosis. Ann Intern Med 2004 Nov 2;141(9):674-682.

43. Setaro JF, Saddler MC, Chen CC, Hoffer PB, Roer DA, Markowitz DM, Meier GH, Gusberg RJ, Black HR. Simplified captopril renography in diagnosis and treatment of renal artery stenosis. Hypertension 1991 Sep;18(3):289-298.

44. Mann SJ, Pickering TG. Detection of renovascular hypertension. State of the art: 1992. Ann Intern Med 1992 Nov 15;117(10):845-853.

45. Vaughan ED Jr. Curable renal hypertension: renin, marker or cause? Question answered. Am J Hypertens 2014 Aug; 27(8):1000-1003.

46. RossiGP,CesariM,Chiesura-Corona M,Miotto D,Semplicini A, Pessina AC. Renal vein renin measurements accurately identify renovascular hypertension caused by total occlusion of the renal artery. J Hypertens 2002 May;20(5):975-984.

47. Novick AC. Current concepts in the management of renovascular hypertension and ischemic renal failure. Am J Kidney Dis 1989 Jun;13(6 Suppl 1):33-37.
48. Hackam DG, Duong-Hua ML, Mamdani M, Li P, Tobe SW, Spence JD, Garg AX. Angiotensin inhibition in renovascular disease: a population-based cohort study. Am Heart J 2008 Sep;156(3):549-555.

49. Hricik DE, Dunn MJ. Angiotensin-converting enzyme inhibitor-induced renal failure: causes, consequences, and diagnostic uses. J Am Soc Nephrol 1990 Dec;1(6):845-858.

50. Chrysochou C, Foley RN, Young JF, Khavandi K, Cheung CM, Kalra PA. Dispelling the myth: the use of renin-angiotensin blockade in atheromatous renovascular disease. Nephrol Dial Transplant 2012 Apr;27(4):1403-1409.

51. Cooper CJ, Murphy TP, Cutlip DE, Jamerson K, Henrich W, Reid DM, Cohen DJ, Matsumoto AH, Steffes M, Jaff MR, et al. Stenting and medical therapy for atherosclerotic renal-artery stenosis. N Engl J Med 2014 Jan;370(1):13-22.

52. ASTRAL Investigators, Wheatley K, Ives N, Gray R, Kalra PA, Moss JG, Baigent C, Carr S, Chalmers N, Eadington D, et al. Revascularization versus medical therapy for renal-artery stenosis. N Engl J Med 2009 Nov 12;361(20):1953-1962.

53. Bax L, Woittiez AJ, Kouwenberg HJ, Mali WP, Buskens E, Beek FJ, Braam B, Huysmans FT, Schultze Kool LJ, Rutten MJ, et al. Stent placement in patients with atherosclerotic renal artery stenosis and impaired renal function: a randomized trial. Ann Intern Med 2009 Jun 16;150(12):840-848.

54. Jenks S, Yeoh SE, Conway BR. Balloon angioplasty, with and without stenting, versus medical therapy for hypertensive patients with renal artery stenosis. Cochrane Database Syst Rev 2014;(12):CD002944.

55. Kumbhani DJ, Bavry AA, Harvey JE, de Souza R, Scarpioni R, Bhatt DL, Kapadia SR. Clinical outcomes after percutaneous revascularization versus medical management in patients with significant renal artery stenosis: a meta-analysis of randomized controlled trials. Am Heart J 2011 Mar;161(3):622-630.

56. Van Jaarsveld BC, Krijnen P, Pieterman H, Derkx FH, Deinum J, Postma CT, Dees A, Woittiez AJ, Bartelink AK, Man in 't Veld AJ, et al. The effect of balloon angioplasty on hypertension in atherosclerotic renal-artery stenosis. Dutch Renal Artery Stenosis Intervention Cooperative Study Group. N Engl J Med 2000 Apr 6;342(14):1007-1014.

57. Plouin PF, Chatellier G, Darné B, Raynaud A. Blood pressure outcome of angioplasty in atherosclerotic renal artery stenosis: a randomized trial. Essai Multicentrique Medicaments vs Angioplastie (EMMA) Study Group. Hypertension 1998 Mar;31(3):823-829.

58. Webster J, Marshall F, Abdalla M, Dominiczak A, Edwards R, Isles CG, Loose H, Main J, Padfield P, Russell IT, et al. Randomized comparison of percutaneous angioplasty vs continued medical therapy for hypertensive patients with atheromatous renal artery stenosis. Scottish and Newcastle Renal Artery Stenosis Collaborative Group. J Hum Hypertens 1998 May;12(5):329-335. 